\title{
Metabolic profile at first-time schizophrenia diagnosis: a population-based cross-sectional study
}

\author{
This article was published in the following Dove Press journal: \\ Neuropsychiatric Disease and Treatment \\ 28 February 2017 \\ Number of times this article has been viewed
}

\author{
Henriette Thisted \\ Horsdal ${ }^{1,2}$ \\ Michael Eriksen Benros ${ }^{2,3}$ \\ Ole Köhler-Forsberg ${ }^{2-4}$ \\ Jesper Krogh ${ }^{3}$ \\ Christiane Gasse ${ }^{1,2,5}$
}

'National Centre for Registerbased Research, Department of Economics and Business Economics, Aarhus BSS, Aarhus University, Aarhus, ${ }^{2}$ The Lundbeck Foundation Initiative for Integrative Psychiatric Research, iPSYCH, Aarhus, ${ }^{3}$ Faculty of Health Sciences, Mental Health Centre Copenhagen, University of Copenhagen, Copenhagen, ${ }^{4}$ Psychosis Research Unit, Aarhus University Hospital, Risskov, ${ }^{5}$ Centre for Integrated Register-Based Research, Aarhus University, Aarhus, Denmark

Correspondence: Henriette Thisted Horsdal

National Centre for Register-based Research, Department of Economics and Business Economics, Aarhus BSS, Aarhus University, Fuglesangs Allé 4, DK-82I0

Aarhus $V$, Denmark

Tel +4587l66035

Email horsdal@econ.au.dk
Objective: Schizophrenia and/or antipsychotic drug use are associated with metabolic abnormalities; however, knowledge regarding metabolic status and physician's monitoring of metabolic status at first schizophrenia diagnosis is sparse. We assessed the prevalence of monitoring for metabolic blood abnormalities and characterized the metabolic profiles in people with a first-time schizophrenia diagnosis.

Methods: This is a population-based cross-sectional study including all adults born in Denmark after January 1, 1955, with their first schizophrenia diagnosis between 2000 and 2012 in the Central Denmark Region. Information on metabolic parameters was obtained from a clinical laboratory information system. Associations were calculated using Wilcoxon rank-sum tests, chi-square tests, logistic regression, and Spearman's correlation coefficients.

Results: A total of 2,452 people with a first-time schizophrenia diagnosis were identified, of whom 1,040 (42.4\%) were monitored for metabolic abnormalities. Among those monitored, $58.4 \%$ had an abnormal lipid profile and $13.8 \%$ had an abnormal glucose profile. People who had previously filled prescription(s) for antipsychotic drugs were more likely to present an abnormal lipid measure $(65.7 \%$ vs $46.8 \%, P<0.001)$ and abnormal glucose profile $(16.4 \%$ vs $10.1 \%, P=0.01)$.

Conclusion: Metabolic abnormalities are common at first schizophrenia diagnosis, particularly among those with previous antipsychotic prescription(s). Increased metabolic abnormalities already present in the early phase of schizophrenia emphasize the need for increased monitoring and management.

Keywords: schizophrenia, metabolism, epidemiology, lipids, glucose

\section{Introduction}

People with schizophrenia have a high prevalence of metabolic abnormalities, ${ }^{1-3}$ and metabolic screening and routine monitoring in this patient group are recommended worldwide..$^{3-5}$

These metabolic abnormalities are considered a serious consequence of antipsychotic treatment but may vary with drug and dose. ${ }^{2,3,5}$ However, schizophrenia per se may be an independent risk factor for metabolic abnormalities. Thus, people with schizophrenia not treated with antipsychotic drugs also have higher prevalence of glucose $e^{6,7}$ and lipid ${ }^{8,9}$ abnormalities compared with individuals without schizophrenia. This may be due to lifestyle factors, such as unhealthy diet and lack of exercise. ${ }^{3}$ In addition, genetic studies have suggested disturbances in metabolic and growth hormone signaling pathways unrelated to antipsychotic treatment ${ }^{10,11}$ and shared genetic risk factors between schizophrenia and type 2 diabetes mellitus. ${ }^{12}$ Furthermore, gender differences in schizophrenia are well known, ${ }^{13,14}$ with women having a higher prevalence of metabolic syndrome than men., ${ }^{1,14}$ 
According to Danish guidelines, blood glucose and lipids should be assessed at first-time schizophrenia diagnosis and thereafter at least once a year. ${ }^{15-17}$ However, knowledge about the amount of metabolic monitoring and status at the earlier phases is sparse on a population-based level. Thus, the objective of our study was to evaluate the Danish routine monitoring practice and to characterize the metabolic profile (blood glucose and lipids) at first-time schizophrenia diagnosis, including the associations with previous antipsychotic prescription(s), gender differences, and subsequent pharmacological treatment for metabolic abnormalities.

\section{Methods}

\section{Setting and design}

We conducted this cross-sectional study within the Central Denmark Region covering a population of $\sim 1,280,000$ inhabitants ( $22 \%$ of the total Danish population). The Danish National Health Service provides tax-supported health care for all inhabitants, guaranteeing free access to general practitioners and hospitals and refunding a variable proportion of the prescription medication costs. The Danish Civil Registration System contains records on gender, date of birth, change of address, date of emigration, and vital status since $1968 .{ }^{18,19}$ The records carry a unique 10-digit civil registration number, assigned to every Danish citizen and used in all Danish registries, enabling unambiguous linkage between them. This study was approved by the Danish Data Protection Agency and the Danish Health and Medicines authority who do not deem patient informed consent necessary as this is register-based research which does not require consent in Denmark.

\section{Study population}

The Danish Psychiatric Central Research Register ${ }^{20}$ has recorded all diagnoses assigned at psychiatric hospitals in Denmark since 1969 with a high validity of schizophrenia diagnoses. ${ }^{21}$ Diagnoses are coded according to the International Classification of Disease, eighth revision (ICD-8) until the end of 1993 and 10th revision (ICD-10) thereafter. We identified all adults (aged $\geq 18$ years) born in Denmark after January 1, 1955, living in Central Denmark Region at first-time schizophrenia diagnosis (ICD-8: 295 excluding 295.79 and ICD-10: F20) between April 1, 2000, and September 30, 2012.

\section{Assessment of metabolic parameters}

The clinical laboratory information system records all test results from specimens submitted for analysis by hospitals and general practitioners in the region. ${ }^{22}$ The database was initiated in the $1990 \mathrm{~s}$, but the data are first considered complete since $2000 .{ }^{22}$ Data include the test name, the test's nomenclature for properties and units (NPU) code and/or a local analysis number, the test result, the measuring unit, and the dates of ordering and carrying out the analysis. We identified all measures for blood glucose (fasting, nonfasting blood glucose, and hemoglobin A1c [HbA1c]) and lipids (total cholesterol, high-density lipoprotein cholesterol [HDL-C], low-density lipoprotein cholesterol [LDL-C], and triglycerides) at baseline (between 90 days before and 90 days after first-time schizophrenia diagnosis). We used the results measured closest to the day of diagnosis. We categorized lipid levels as normal/abnormal according to the criteria set by the National Cholesterol Education Program (NCEP), ${ }^{23}$ and blood glucose levels into normal, prediabetes, and diabetes according to the criteria set by the American Diabetes Association (ADA). ${ }^{24}$ Thresholds, NPU codes, and analysis numbers are given in Table S1.

\section{Assessment of baseline characteristics}

We obtained information on previous hospitalizations for mental disorders and somatic diseases from the Danish Psychiatric Central Research Register ${ }^{20}$ and the Danish National Patient Registry ${ }^{25}$ (defined by ICD codes; Table S2). The Danish National Patient Registry was established in 1977 and contains data on all hospitalizations from nonpsychiatric hospitals, including dates of admission and discharge.

The Danish National Prescription Registry ${ }^{26}$ contains detailed data from 1995 onward on all prescribed drugs dispensed at all Danish pharmacies, name and type of drug according to the Anatomical Therapeutic Chemical (ATC) classification system, defined daily dose (DDD), and date of dispensing. We traced all prescriptions for psychotropic drugs (antipsychotics [first-generation antipsychotics $\{$ FGAs $\}$ and second-generation antipsychotics $\{$ SGAs $\}]$, antidepressants, and benzodiazepines), antidiabetic drugs, antiobesity drugs, lipid-lowering drugs, and antihypertensive drugs (defined by ATC codes; Table S3) ever filled before the date of firsttime schizophrenia diagnosis. Since women with polycystic ovary syndrome may be treated with metformin, we excluded all metformin prescriptions redeemed by women aged 20-39 years to avoid misclassification of these potentially nondiabetic patients. We calculated the total amount (DDD) of antipsychotics redeemed prior to first-time schizophrenia diagnosis by summing all antipsychotic DDDs for each individual. Finally, based on education registries, ${ }^{27}$ we classified the people with schizophrenia according to their highest 
completed education level prior to first-time schizophrenia diagnosis, dichotomized in primary school (lowest) and a combined group of higher level education.

\section{Assessment of treatment for metabolic abnormalities}

To evaluate the level of treatment for metabolic abnormalities, we further identified prescriptions for lipid-lowering drugs and antidiabetic drugs filled in the year after baseline metabolic blood test.

\section{Statistical analysis}

Descriptive summary statistics (median, interquartile range [IQR]) were generated for continuous variables. For discrete variables, the number of people and percentages are given. Normality of distribution was tested with the Shapiro-Wilk test. Differences between groups in continuous variables were analyzed by Wilcoxon rank-sum test, and differences between proportions were analyzed by chi-square tests. We also applied logistic regression analyses to examine the association of previous use of antipsychotic drugs and metabolic abnormalities reporting odds ratios (ORs) and 95\% confidence intervals (CIs) adjusting for age, gender, time since first psychiatric diagnosis, year of diagnosis, treatment setting (inpatient or outpatient status), diabetes (diagnosis and/or drug), dyslipidemia (diagnosis and/or drug), and obesity (diagnosis and/or drug).

Since the national guidelines including routine metabolic monitoring were implemented in 2004, ${ }^{17}$ we also compared the time period before the implementation (2000-2004) with the time period after the implementation (2005-2012). Correlations between the metabolic parameters and amount of antipsychotic treatment as well as time since first psychiatric diagnosis were tested by Spearman's correlation coefficient.

Since different antipsychotics have different effects on the metabolism, we divided the antipsychotics into FGAs and SGAs.

Finally, because the inclusion of results from blood tests within 90 days of first-time schizophrenia diagnosis yields the risk of abnormal findings related to other conditions/ hospitalizations than schizophrenia, eg, somatic diseases (ie, the blood test could have been based on another indication and thus not schizophrenia monitoring), we performed several sensitivity analyses looking at different time windows (within 14, 30, and 60 days of first-time schizophrenia diagnosis).

All the analyses were two sided and performed using Stata (StataCorp LP, College Station, TX, USA) version 13.1.
The statistical significance level was set at 0.05 in all the analyses.

\section{Results}

We identified 2,452 adult (aged $\geq 18$ years) people with a first-time schizophrenia diagnosis in Central Denmark Region during the study period. A total of 1,040 (42.4\%) were monitored for lipid metabolism and/or blood glucose at baseline. Among these, the median age was 25.7 years (IQR: 21.9-33.6) and 455 (43.8\%) were women. The proportion of people monitored increased from $19.2 \%$ in 2001 to $70.7 \%$ in 2011 (Figure 1), with a significant increase in both monitoring of lipids (from $3.6 \%$ to $40.5 \%$ ) and glucose (from $22.1 \%$ to $51.5 \%$ ) from 2000-2004 (before guideline implementation) to 2005-2012 (both $P<0.001$ ). People with metabolic blood monitoring were younger, had higher levels of education and more comorbid diseases, were more often diagnosed with paranoid schizophrenia and inpatients at first schizophrenia diagnosis, and had redeemed more prescriptions for metabolic diseases (all $P<0.05$; Table S4).

\section{Metabolic profile at first-time schizophrenia diagnosis}

Based on the available metabolic blood tests, a total of $58.4 \%$ had an abnormal lipid profile based on at least one abnormal lipid measure, $56.1 \%$ had $\geq 2,42.8 \%$ had $\geq 3$, and $35.0 \%$ had 4 abnormal lipid measures. The prevalence of abnormal lipid profiles was $64.7 \%$ during $2000-2004$ and 58.0\% during 2005-2012 ( $P=0.44)$.

Prediabetes was detected in $10.4 \%$ and diabetes in $3.4 \%$. The prevalence of abnormal glucose profiles (prediabetes/ diabetes) was $10.5 \%$ during 2000-2004 and 14.7\% during 2005-2012 $(P=0.15)$.

\section{Metabolic profile according to previous prescriptions for antipsychotic drugs}

Among the 1,040 people with baseline metabolic blood monitoring, 615 (59.1\%) had redeemed prescription(s) for antipsychotic drugs before their first-time schizophrenia diagnosis. These people were older at first schizophrenia diagnosis, had a longer total duration of psychiatric illness, more psychiatric comorbidity, and more often diagnosed with paranoid schizophrenia, and they had redeemed more prescriptions for antidepressants and benzodiazepines (all $P<0.05$; Table S5). People with schizophrenia with previous prescription(s) for antipsychotic drugs had higher prevalence of obesity (7.5\% vs $2.4 \%, P<0.001)$ and dyslipidemia ( $1.8 \%$ vs $0 \%$, $P=0.006$ ), and were more likely to redeem prescription(s) for 


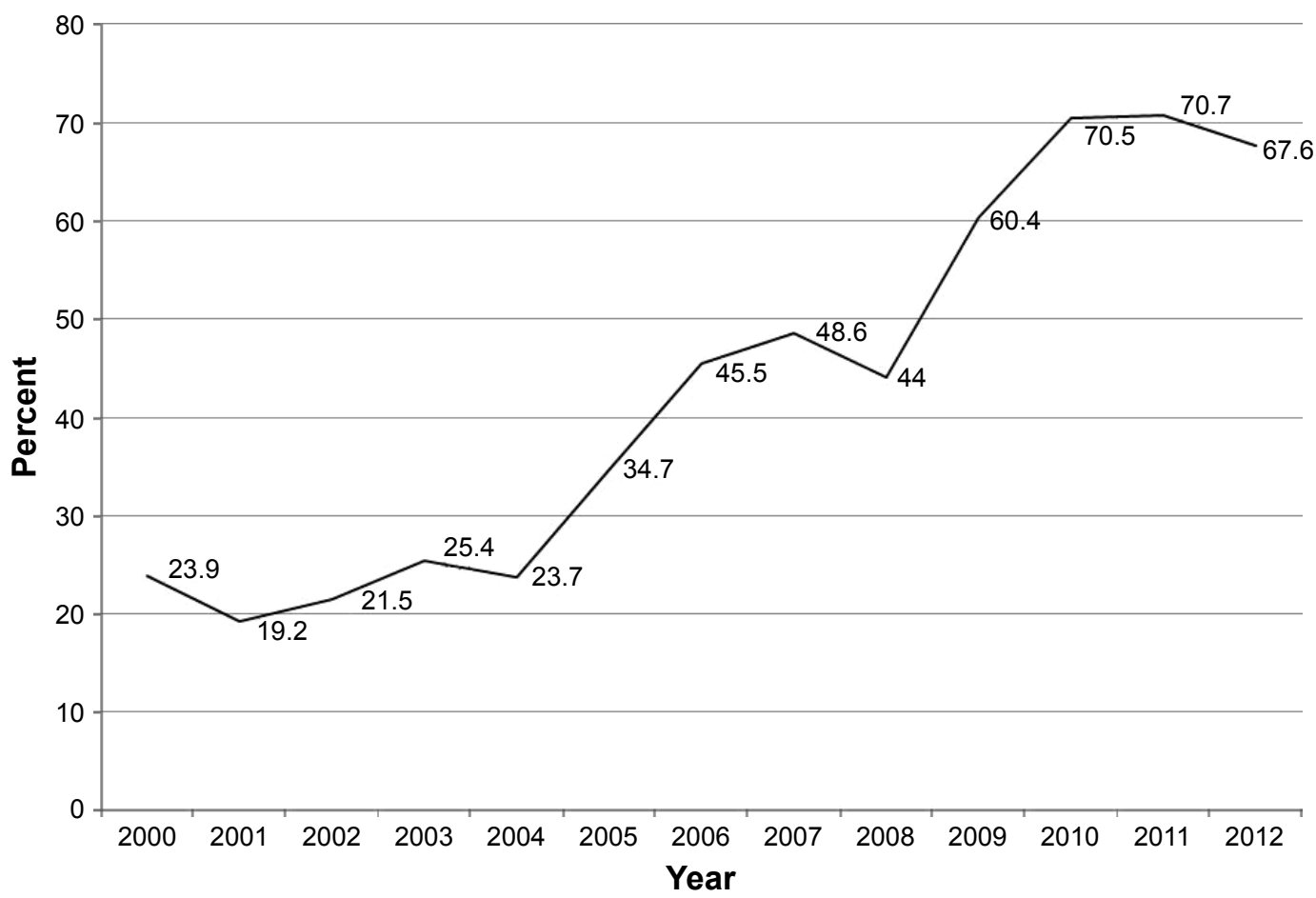

Figure I Percentages of people with a first-time schizophrenia diagnosis with any metabolic blood monitoring within 90 days before diagnosis and 90 days after diagnosis from 2000 to 2012 .

antiobesity preparations (7.5\% vs $3.1 \%, P=0.002)$ and lipidlowering drugs $(3.4 \%$ vs $0.2 \%, P<0.001)$ at baseline, than people with schizophrenia without previous prescription(s) for antipsychotic drugs. A total of $3.1 \%$ with prior antipsychotic prescription(s) had a previous diabetes diagnosis compared with $1.4 \%$ without prior antipsychotic prescription(s) $(P=0.08)$, and $3.4 \%$ versus $1.7 \%$ had redeemed prescription(s) for antidiabetic drugs $(P=0.08)$ before baseline blood test.

Table 1 presents baseline metabolic parameters among schizophrenia patients without and with prior antipsychotic drugs. People who had filled prescription(s) for antipsychotic drug(s) before first-time schizophrenia diagnosis had not only an overall higher prevalence of abnormal lipid profiles $(65.7 \%$ vs $46.8 \%, P<0.001)$ but also higher total cholesterol, higher triglyceride levels, and lower HDL-C levels (Table 1). Likewise, these people had significant higher non-fasting glucose levels and showed a trend toward higher levels of $\mathrm{HbAlc}$ and fasting glucose (Table 1). Combining HbAlc, non-fasting and fasting glucoses resulted in a higher overall prevalence of prediabetes/diabetes in people with schizophrenia with previous antipsychotic drugs use $(16.4 \%$ vs $10.1 \%, P=0.01$; Table 1). These associations of previous use of antipsychotic drugs and metabolic abnormalities were also found in the crude estimates from the logistic regression analyses (abnormal lipid profile: $\mathrm{OR}=2.18$, 95\% CI: $1.58-3.02$, and prediabetes/diabetes: $\mathrm{OR}=1.75$,
95\% CI: 1.18-2.58). After adjustment, only the association with abnormal lipid profile remained statistically significant (abnormal lipid profile: adjusted $\mathrm{OR}=1.96,95 \% \mathrm{CI}$ : 1.39-2.74, and prediabetes/diabetes: adjusted $\mathrm{OR}=1.23,95 \%$ CI: 0.80-1.91).

Regarding cumulative dose effects of previous antipsychotic drug use, the total amount of antipsychotic drug(s) before first-time schizophrenia diagnosis correlated significantly with total cholesterol, HDL-C (inverse), triglycerides, non-fasting and fasting glucose, and $\mathrm{HbA} 1 \mathrm{c}$, while time since the first psychiatric diagnosis significantly correlated with triglycerides and non-fasting and fasting glucose (Table 2).

\section{Metabolic profile according to gender}

Baseline differences between men and women are presented in Table S6. Women were younger, more comorbid, and more likely to have redeemed prescription(s) for antidepressants and benzodiazepines (all $P<0.05$ ). At baseline, obesity was more common in women ( $7.5 \%$ vs $3.8 \%, P=0.009)$, and women had redeemed more prescription(s) for antiobesity preparations $(9.2 \%$ vs $2.9 \%, P<0.001)$. We found no gender differences in the prevalence of dyslipidemia (1.1 vs $1.0 \%, P=0.91)$ and use of lipid-lowering drugs $(2.4 \%$ vs $1.9 \%, P=0.55)$, nor in the prevalence of diabetes diagnoses $(2.4 \%$ vs $2.4 \%, P=0.98)$ and antidiabetic drugs $(2.6 \%$ vs $2.7 \%, P=0.92)$ at baseline. 
Table I Baseline metabolic parameters among people with schizophrenia by previous antipsychotic drug prescription(s)

\begin{tabular}{|c|c|c|c|c|}
\hline Characteristics & $\begin{array}{l}\text { Without prior } \\
\text { antipsychotic drugs }\end{array}$ & $\begin{array}{l}\text { With prior } \\
\text { antipsychotic drugs }\end{array}$ & Total & $P$-value \\
\hline $\mathrm{N}(\%)$ & $425(40.9)$ & $615(59.1)$ & $\mathrm{I}, 040(100)$ & $<0.001$ \\
\hline \multicolumn{5}{|l|}{ Lipid metabolism } \\
\hline \multicolumn{5}{|l|}{ Total cholesterol $(n=622)$} \\
\hline Median (IQR), mmol/L & $4.5(3.9-5.2)$ & $4.7(4.1-5.4)$ & $4.6(4.0-5.3)$ & \multirow[t]{2}{*}{0.05} \\
\hline Normal (<5.2 mmol/L), n (\%) & $180(75.6)$ & $265(69.0)$ & $445(71.6)$ & \\
\hline Increased (5.2-6.3 mmol/L), n (\%) & $39(16.4)$ & $85(22.1)$ & $124(19.9)$ & \multirow[t]{2}{*}{0.18} \\
\hline High ( $\geq 6.3 \mathrm{mmol} / \mathrm{L}), \mathrm{n}(\%)$ & $19(8.0)$ & $34(8.9)$ & $53(8.5)$ & \\
\hline \multicolumn{5}{|l|}{ HDL-C ( $n=597)$} \\
\hline Median (IQR), mmol/L & $1.3(1.1-1.5)$ & I.I (0.9-I.4) & $1.2(1.0-1.5)$ & \multirow[t]{2}{*}{$<0.001$} \\
\hline Low (F: <I.3, M: <I.0 mmol/L), n (\%) & $60(25.6)$ & $170(46.8)$ & $230(38.5)$ & \\
\hline Normal (F: I.3-I.6, M: I.0-I.6 mmol/L), n (\%) & II 8 (50.4) & $132(36.4)$ & $250(41.9)$ & \multirow[t]{2}{*}{$<0.001$} \\
\hline High ( $\geq 1.6$ mmol/L), n (\%) & $56(23.9)$ & $61(16.8)$ & $117(19.6)$ & \\
\hline \multicolumn{5}{|l|}{ LDL-C ( $n=578)$} \\
\hline Median (IQR), mmol/L & $2.7(2.1-3.3)$ & $2.8(2.2-3.5)$ & $2.8(2.2-3.4)$ & \multirow[t]{2}{*}{0.17} \\
\hline Normal (<3.4 mmol/L), n (\%) & $174(76.6)$ & $255(72.7)$ & $429(74.2)$ & \\
\hline Increased (3.4-4.I mmol/L), n (\%) & $34(15.0)$ & $66(18.8)$ & $100(17.3)$ & \multirow[t]{2}{*}{0.48} \\
\hline High ( $\geq 4.1$ mmol/L), n (\%) & $19(8.4)$ & $30(8.5)$ & $49(8.5)$ & \\
\hline \multicolumn{5}{|l|}{ Triglycerides $(\mathrm{n}=572)$} \\
\hline Median (IQR), mmol/L & $1.0(0.7-1.6)$ & $1.3(0.9-1.9)$ & $1.2(0.8-1.8)$ & \multirow[t]{2}{*}{$<0.001$} \\
\hline Normal (<l.7 mmol/L), n (\%) & $175(78.8)$ & $229(65.4)$ & $404(70.6)$ & \\
\hline Increased (I.7-2.3 mmol/L), n (\%) & $29(13.1)$ & $59(16.9)$ & $88(15.4)$ & \multirow[t]{2}{*}{0.001} \\
\hline High ( $\geq 2.3 \mathrm{mmol} / \mathrm{L}), \mathrm{n}(\%)$ & $18(8.1)$ & $62(17.7)$ & $80(14.0)$ & \\
\hline \multicolumn{5}{|c|}{ Abnormal lipid profile ${ }^{a}$ (total cholesterol, HDL-C, LDL-C, and/or triglycerides) $(n=644)$} \\
\hline Normal, n (\%) & $133(53.2)$ & $135(34.3)$ & $268(4 I .6)$ & \multirow{2}{*}{$<0.001$} \\
\hline Abnormal, n (\%) & $117(46.8)$ & $259(65.7)$ & $376(58.4)$ & \\
\hline \multicolumn{5}{|l|}{ Carbohydrate metabolism } \\
\hline \multicolumn{5}{|l|}{ Non-fasting glucose $(n=765)$} \\
\hline Median (IQR), mmol/L & $5.4(4.9-5.9)$ & $5.6(5.1-6.3)$ & $5.5(5.1-6.2)$ & \multirow[t]{2}{*}{$<0.001$} \\
\hline Normal (<7.8 mmol/L), n (\%) & $298(95.8)$ & $415(91.4)$ & $713(93.2)$ & \\
\hline Prediabetes (7.8-II.0 mmol/L), n (\%) & $8(2.6)$ & $31(6.8)$ & $39(5.1)$ & \multirow[t]{2}{*}{0.03} \\
\hline Diabetes (>II.0 mmol/L), n (\%) & $5(1.6)$ & $8(1.8)$ & $13(1.7)$ & \\
\hline \multicolumn{5}{|l|}{ Fasting glucose $(n=353)$} \\
\hline Median (IQR), mmol/L & $5.2(4.9-5.6)$ & $5.4(5.0-5.8)$ & $5.3(5.0-5.7)$ & \multirow[t]{2}{*}{0.09} \\
\hline Normal (<5.6 mmol/L), n (\%) & $105(75.5)$ & $146(68.2)$ & $25 I(7 I . I)$ & \\
\hline Prediabetes (5.6-6.9 mmol/L), n (\%) & $26(18.7)$ & $52(24.3)$ & $78(22.1)$ & \multirow[t]{2}{*}{0.33} \\
\hline Diabetes (>6.9 mmol/L), n (\%) & $8(5.8)$ & $16(7.5)$ & $24(6.8)$ & \\
\hline \multicolumn{5}{|l|}{$\mathrm{HbAlc}(\mathrm{n}=139)$} \\
\hline Median (IQR), \% & $5.3(5.1-5.8)$ & $5.4(5.2-5.8)$ & $5.4(5.2-5.8)$ & \multirow[t]{2}{*}{0.14} \\
\hline Normal ( $\leq 5.6 \%), \mathrm{n}(\%)$ & $29(72.5)$ & $69(69.7)$ & $98(70.5)$ & \\
\hline Prediabetes (5.7\%-6.4\%), n (\%) & $5(12.5)$ & $16(16.2)$ & $21(15.1)$ & 0.86 \\
\hline Diabetes ( $\geq 6.5 \%), \mathrm{n}(\%)$ & $6(15.0)$ & $14(14.1)$ & $20(14.4)$ & \\
\hline $\mathrm{HbAlc}$, non-fasting, and/or fasting glucose $\mathrm{e}^{\mathrm{b}}(\mathrm{n}=98$ & & & & \\
\hline Normal, n (\%) & $365(89.9)$ & $484(83.6)$ & $849(86.2)$ & \\
\hline Prediabetes, n (\%) & $29(7.1)$ & $73(12.6)$ & $102(10.4)$ & 0.01 \\
\hline Diabetes, n (\%) & $12(3.0)$ & $22(3.8)$ & $34(3.4)$ & \\
\hline
\end{tabular}

Notes: a Defined by lipid measure(s) (total cholesterol $\geq 5.2 \mathrm{mmol} / \mathrm{L}, \mathrm{HDL}-\mathrm{C}<\mathrm{I} .3 \mathrm{mmol} / \mathrm{L}$ among women and $<\mathrm{I} .0 \mathrm{mmol} / \mathrm{L}$ among men, LDL-C $\geq 3.4 \mathrm{mmol} / \mathrm{L}$, and/or triglycerides $\geq 1.7 \mathrm{mmol} / \mathrm{L}$ ) closest to first-time schizophrenia diagnosis. ${ }^{~}$ Defined by the blood glucose value (either $\mathrm{HbAlc}>5.7 \%$, non-fasting $\geq 7.8 \mathrm{mmol} / \mathrm{L}$, or fasting blood glucose $\geq 5.6 \mathrm{mmol} / \mathrm{L}$ ) closest to first-time schizophrenia diagnosis.

Abbreviations: F, female; HbAIc, hemoglobin AIc; HDL-C, high-density lipoprotein cholesterol; IQR, interquartile range; LDL-C, low-density lipoprotein cholesterol; M, male.

Based on the metabolic blood tests, women had significantly higher median HDL-C levels than men, but even with higher median HDL-C levels and a greater proportion with high HDL-C levels more women had HDL-C levels below the recommended levels (Table 3). Likewise, even though women had lower LDL-C cholesterol and triglycerides levels, abnormal lipid profiles were more frequent among women (Table 3). Women had significantly lower non-fasting 
Table 2 Correlation between metabolic parameters and time since the first psychiatric diagnosis and total amount of antipsychotic treatment prior to schizophrenia diagnosis

\begin{tabular}{|c|c|c|c|c|c|c|}
\hline \multirow[t]{2}{*}{$\begin{array}{l}\text { Metabolic } \\
\text { parameters }\end{array}$} & \multicolumn{3}{|c|}{ Time since first psychiatric diagnosis } & \multicolumn{3}{|c|}{$\begin{array}{l}\text { Total amount (DDD) of antipsychotic } \\
\text { treatment }\end{array}$} \\
\hline & $\mathbf{n}$ & Spearman's $\rho$ & $P$-value & $\mathbf{n}$ & Spearman's $\rho$ & $P$-value \\
\hline Total cholesterol & 622 & 0.0622 & 0.12 & 622 & 0.0999 & 0.01 \\
\hline HDL-C & 597 & -0.0378 & 0.36 & 597 & -0.1853 & $<0.001$ \\
\hline LDL-C & 578 & 0.0257 & 0.54 & 578 & 0.0652 & 0.12 \\
\hline Triglycerides & 572 & 0.1125 & 0.007 & 572 & 0.2339 & $<0.001$ \\
\hline Non-fasting glucose & 765 & 0.1497 & $<0.001$ & 765 & 0.2108 & $<0.001$ \\
\hline Fasting glucose & 353 & 0.1233 & 0.02 & 353 & 0.1179 & 0.03 \\
\hline $\mathrm{HbAlc}$ & 139 & 0.1140 & 0.18 & 139 & 0.1832 & 0.03 \\
\hline
\end{tabular}

Abbreviations: DDD, defined daily dose; HbAIc, hemoglobin AIc; HDL-C, high-density lipoprotein cholesterol; LDL-C, low-density lipoprotein cholesterol.

glucose than men. Despite that, when combining the blood glucose measures, we found no gender differences in the prevalence of abnormal glucose profile (Table 3).

\section{Treatment for metabolic abnormalities in the year after abnormal metabolic blood test}

Among the 345 people with $\geq 2$ abnormal lipid measures, $24(7.0 \%)$ had redeemed prescription(s) for lipid-lowering drugs in the year after the blood test. This was $9.3 \%$ among people with $\geq 3$ abnormal lipid measures and $11.6 \%$ among those with abnormality in all four lipid measures. Regarding time period differences, $13.3 \%$ with $\geq 2$ abnormal lipid measures during 2000-2004 had redeemed prescription(s) for lipid-lowering drugs within the following year versus $6.7 \%$ during $2005-2012(P=0.32)$. Among the 34 people with blood glucose levels in the diabetes range, $55.9 \%$ redeemed a prescription for an antidiabetic drug during the subsequent year. This was $33.3 \%$ in $2000-2004$ and $58.1 \%$ in $2005-2012(P=0.41)$.

We found no gender differences concerning lipidlowering and antidiabetic treatment among people with $\geq 2$ abnormal lipid measures and/or blood glucose levels in the diabetic range (data not shown).

\section{Sensitivity analyses}

We found no difference in the prevalence of abnormal lipid profiles between people redeeming prescription(s) for FGAs and people redeeming prescription(s) for SGAs $(59.3 \%$ vs $61.9 \%, P=0.72$ ). However, we found higher prevalence of prediabetes/diabetes in people redeeming prescription(s) for FGAs compared with people redeeming prescription(s) for SGAs $(24.4 \%$ vs $11.3 \%, P=0.01)$.

All sensitivity analyses within different time windows for identification of the metabolic measure at first-time schizophrenia diagnosis supported our primary results. Thus, identifying lipid measures within 14, 30, and 60 days from first-time schizophrenia diagnosis resulted in 51.8\%, $55.2 \%$, and $57.5 \%$ with an abnormal lipid profiles. Similarly, combined blood glucose results identified within these time frames resulted in $13.7 \%, 13.8 \%$, and $14.2 \%$ with abnormal glucose profiles.

\section{Discussion}

The current study represents the largest investigation to date regarding monitoring and status of metabolic profiles at firsttime schizophrenia diagnosis, covering 1,040 people with a median age of 26.7 years in a Danish routine clinical setting. Overall, metabolic monitoring among people with a first-time schizophrenia diagnosis has improved during the study period from 2000 to 2012, with a large increase after implementation of guidelines recommending metabolic awareness; however, it remains suboptimal with $71 \%$ as the highest monitoring rate. More than half of the people monitored had an abnormal lipid profile and $14 \%$ had abnormal glucose profiles at first-time schizophrenia diagnosis. This was particularly present among people who had redeemed prescription(s) for antipsychotic drugs. However, even among people without prior antipsychotic prescription(s), 47\% had abnormal lipid profiles and $10 \%$ had an abnormal glucose profile.

The inadequate monitoring for the presence of metabolic disease among people with schizophrenia has also been shown in prior studies, such as the Clinical Antipsychotic Trials of Intervention Effectiveness (CATIE) schizophrenia trial. ${ }^{1}$ Importantly, the inadequate monitoring continued despite implementation of guidelines that nevertheless significantly improved the monitoring in the Danish setting.

The metabolic status among people with first-time schizophrenia in our study is comparable with the metabolic status of individuals $\sim 20$ years older in the general population, ${ }^{28,29}$ which 


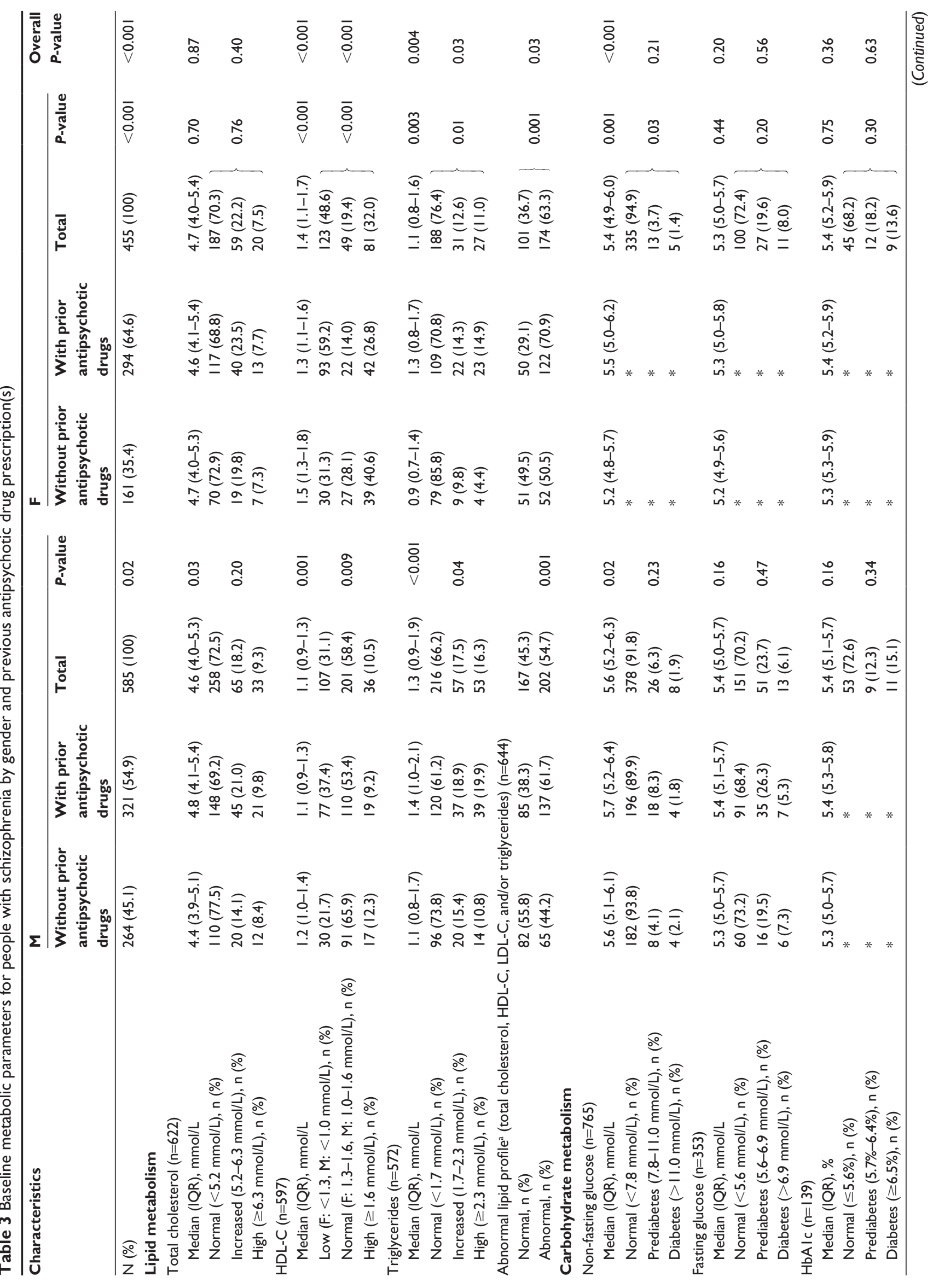




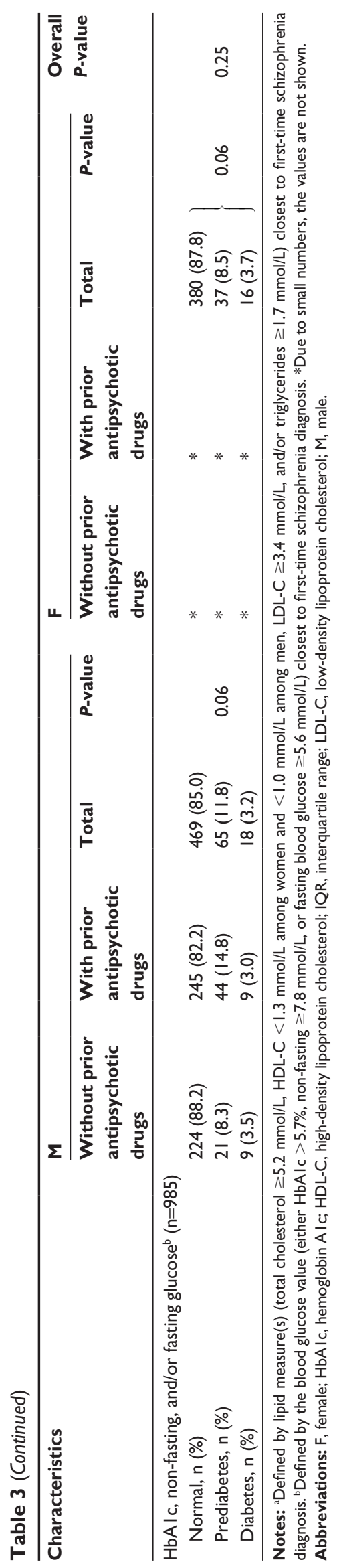

suggests that people with schizophrenia are at substantial increased cardiovascular risk at a younger age, potentially contributing to the increased mortality from cardiovascular disease and reduced life expectancy observed among people with schizophrenia. ${ }^{30}$ Regarding relevant treatment for metabolic abnormalities, we showed that only $11.6 \%$ with abnormalities in all four lipid measures had redeemed prescription(s) for lipid-lowering drugs and $55.9 \%$ of people with blood glucose values in the diabetic range had redeemed prescription(s) for antidiabetic drugs during the subsequent year. This relative low prevalence of treatment for metabolic abnormalities in people with schizophrenia is consistent with the CATIE trial, in which $69.9 \%$ of the patients with diabetes received antidiabetic drugs, and only $12.0 \%$ of the patients with hyperlipidemia received lipid-lowering medication. ${ }^{31}$

Our findings of metabolic abnormalities already being present in people with a first-time schizophrenia diagnosis are consistent with several other studies. ${ }^{32-34}$ However, the extent of metabolic abnormalities differed slightly between the studies, probably due to different study populations.

In our study, metabolic abnormalities were more frequent among people with schizophrenia with prior prescription(s) for antipsychotic drugs, which is in agreement with other studies including the CATIE trial. ${ }^{34-37}$ It is known that some of the antipsychotic drugs (especially the SGAs) are associated with metabolic abnormalities ${ }^{2,3,5}$ and that these effects also vary between different antipsychotic drugs. ${ }^{35-37}$ However, the finding of higher prevalence of prediabetes/diabetes among users of FGAs in our study may be confounded by indication, ie, FGA may have been prescribed to people with higher risk of metabolic syndrome or diabetes, whereas SGA may have been prescribed to people with anticipated lower risk of metabolic or diabetes risk.

The level of metabolic parameters correlated with both the amount of antipsychotic treatment prior to first-time schizophrenia diagnosis and the time since the first psychiatric diagnosis, which is consistent with previous findings $\mathrm{s}^{33,34}$ and supports both the hypothesis of a direct effect of the schizophrenia disorder and of antipsychotic medication on the metabolic abnormalities.

Our findings that even people without prior prescription(s) for antipsychotic drugs had a high prevalence of metabolic abnormalities also support genetic studies associating schizophrenia with metabolic disturbances ${ }^{10,11}$ and disease. ${ }^{12}$ Nevertheless, we cannot determine the impact of prior unhealthy lifestyle on the observed metabolic measures.

Regarding possible gender differences, none were observed concerning abnormal glucose profiles, which are in 
agreement with most other studies using the same thresholds as we did. ${ }^{1,32,34}$ A previous study by Correll et $\mathrm{al}^{34}$ concluded that women had glucose-defined diabetes more often than men; however, this was based on very few observations. The CATIE trial showed that female gender was associated with abnormal glucose levels based on the threshold set by the NCEP Adult Treatment Protocol III ( $\geq 6.1 \mathrm{mmol} / \mathrm{L})$, but not based on the ADA threshold ( $\geq 5.6 \mathrm{mmol} / \mathrm{L}),{ }^{1}$ which we used.

However, women were more likely to present abnormal lipid profiles, with higher HDL-C and lower LDL-C and triglycerides levels in our study. Several other studies also showed that women had higher HDL-C and lower triglyceride levels, but with no gender differences in the prevalence of abnormal lipid profiles. ${ }^{32,34}$ Despite higher HDL-C levels among women, more women than men also had HDL-C levels below the recommended levels, which was also observed in the CATIE trial. ${ }^{1}$

\section{Strengths and limitations}

The main strengths of this study are its large size, its populationbased design, and its ability to link different data sources. As these data sources comprise complete population data, our results reflect the daily clinical practice in the Central Denmark Region. Furthermore, all the data were prospectively collected, avoiding the potential difficulties with any recall bias. The validity of the schizophrenia diagnosis in the registers is high, ${ }^{21}$ but by only including people with schizophrenia with metabolic measures, we may have introduced selection bias as these were more severe cases, thus limiting generalizability. Further, we might have misclassified the antipsychotic drug users due to lack of compliance and lack of knowledge about inhospital treatment; however, such misclassification will most likely bias the association toward null. Finally, in spite of including several potentially confounding factors, we lack information on other factors influencing blood levels of lipids and glucose, such as diet, exercise, and smoking. In contrast, it could be argued that not all the included covariates should be considered true confounding factors, but rather intermediate steps in the association between use of antipsychotic drugs and metabolic abnormalities, whereby we may in theory have underestimated the real effect by adjusting for these covariates.

\section{Conclusion}

Less than half of the people with first-time schizophrenia were monitored for metabolic status at diagnosis. Metabolic abnormalities were frequent and most pronounced among people already treated with antipsychotic drugs.
The metabolic profile was comparable with the profile in a much older general population leaving people with schizophrenia at increased cardiovascular risk, and despite abnormal profiles many did not receive treatment for their metabolic abnormalities during the subsequent year. The high prevalence of metabolic abnormalities and the lack of intervention emphasize the need for screening, monitoring, and treatment among people with a first-time schizophrenia diagnosis.

\section{Acknowledgment}

This research has received funding from the European Community's Seventh Framework Programme (FP7/2007-2013) under grant agreement number 279227.

\section{Disclosure}

Christiane Gasse received unrestricted research grants from Eli-Lilly and Lundbeck A/S and funding through research collaboration with LA-SER Analytica and received support from the Innovative Medicines Initiative Joint Undertaking resources, which were composed of financial contribution from the European Union's Seventh Framework Programme (FP7/2007-2013) and EFPIA companies'. Henriette Thisted Horsdal, Michael Eriksen Benros, Ole Köhler-Forsberg, and Jesper Krogh report no conflicts of interest in this work.

\section{References}

1. McEvoy JP, Meyer JM, Goff DC, et al. Prevalence of the metabolic syndrome in patients with schizophrenia: baseline results from the Clinical Antipsychotic Trials of Intervention Effectiveness (CATIE) schizophrenia trial and comparison with national estimates from NHANES III. Schizophr Res. 2005;80(1):19-32.

2. McDaid TM, Smyth S. Metabolic abnormalities among people diagnosed with schizophrenia: a literature review and implications for mental health nurses. J Psychiatr Ment Health Nurs. 2015;22(3):157-170.

3. De Hert M, Schreurs V, Vancampfort D, van Winkel R. Metabolic syndrome in people with schizophrenia: a review. World Psychiatry. 2009; 8(1):15-22.

4. De Hert M, Vancampfort D, Correll CU, et al. Guidelines for screening and monitoring of cardiometabolic risk in schizophrenia: systematic evaluation. Br J Psychiatry. 2011;199(2):99-105.

5. De Hert M, Van Eyck D, De Nayer A. Metabolic abnormalities associated with second generation antipsychotics: fact or fiction? Development of guidelines for screening and monitoring. Int Clin Psychopharmacol. 2006;21(suppl 2):S11-S15.

6. Ryan MC, Collins P, Thakore JH. Impaired fasting glucose tolerance in first-episode, drug-naive patients with schizophrenia. Am J Psychiatry. 2003;160(2):284-289.

7. Spelman LM, Walsh PI, Sharifi N, Collins P, Thakore JH. Impaired glucose tolerance in first-episode drug-naive patients with schizophrenia. Diabet Med. 2007;24:481-485.

8. Ryan MC, Flanagan S, Kinsella U, Keeling F, Thakore JH. The effects of atypical antipsychotics on visceral fat distribution in first episode, drugnaive patients with schizophrenia. Life Sci. 2004;74(16):1999-2008.

9. Thakore JH, Mann JN, Vlahos I, Martin A, Reznek R. Increased visceral fat distribution in drug-naive and drug-free patients with schizophrenia. Int J Obes Relat Metab Disord. 2002;26(1):137-141. 
10. Guest PC, Wang L, Harris LW, et al. Increased levels of circulating insulin-related peptides in first-onset, antipsychotic naive schizophrenia patients. Mol Psychiatry. 2010;15:118-119.

11. Van Beveren NJ, Schwarz E, Noll R, et al. Evidence for disturbed insulin and growth hormone signaling as potential risk factors in the development of schizophrenia. Transl Psychiatry. 2014;4:e430.

12. Hansen T, Ingason A, Djurovic S, et al. At-risk variant in TCF7L2 for type II diabetes increases risk of schizophrenia. Biol Psychiatry. 2011; 70(1):59-63.

13. Hafner H. Gender differences in schizophrenia. Psychoneuroendocrinology. 2003;28(suppl 2):17-54.

14. Ochoa S, Usall J, Cobo J, Labad X, Kulkarni J. Gender differences in schizophrenia and first-episode psychosis: a comprehensive literature review. Schizophr Res Treatment. 2012;2012:916198.

15. Kompetencecenter for Klinisk kvalitet og Sundhedsinformatik Vest. Den Nationale Skizofrenidatabase - Dokumentalistrapport. [The National Schizophrenia database - Documentalist report]. Aarhus N: Kompetencecenter for Klinisk kvalitet og Sundhedsinformatik Vest; 2014. Danish.

16. Psykiatrien i Region Midtjylland. Diagnostik og udredning af voksne for skizofreni, fallespsykiatrisk retningslinje. [Diagnostics and examination of adults with schizophrenia, a common psychiatric guideline]. Viborg: Psykiatrien i Region Midtjylland; 2014. Danish.

17. Sundhedsstyrelsen CfEoMT. Referenceprogram for skizofreni. [Evidence based guidelines in schizophrenia]. København: Sundhedsstyrelsen; 2004. Danish.

18. Pedersen CB, Gotzsche H, Moller JO, Mortensen PB. The Danish civil registration system. A cohort of eight million persons. Dan Med Bull. 2006;53(4):441-449.

19. Pedersen CB. The Danish civil registration system. Scand J Public Health. 2011;39(7 suppl):22-25.

20. Mors O, Perto GP, Mortensen PB. The Danish psychiatric central research register. Scand J Public Health. 2011;39(7 suppl):54-57.

21. Uggerby P, Ostergaard SD, Roge R, Correll CU, Nielsen J. The validity of the schizophrenia diagnosis in the Danish psychiatric central research register is good. Dan Med J. 2013;60(2):A4578.

22. Grann AF, Erichsen R, Nielsen AG, Froslev T, Thomsen RW. Existing data sources for clinical epidemiology: the clinical laboratory information system (LABKA) research database at Aarhus University, Denmark. Clin Epidemiol. 2011;3:133-138.

23. National Cholesterol Education Program (NCEP) Expert Panel on Detection, Evaluation, and Treatment of High Blood Cholesterol in Adults (Adult Treatment Panel III). Third Report of the National Cholesterol Education Program (NCEP) expert panel on detection, evaluation, and treatment of high blood cholesterol in adults (adult treatment panel III) final report. Circulation. 2002;106(25):3143-3421.
24. American Diabetes Association. Diagnosis and classification of diabetes mellitus. Diabetes Care. 2014;37(suppl 1):S81-S90.

25. Lynge E, Sandegaard JL, Rebolj M. The Danish national patient register. Scand J Public Health. 2011;39(7 suppl):30-33.

26. Kildemoes HW, Sorensen HT, Hallas J. The Danish national prescription registry. Scand J Public Health. 2011;39(7 suppl):38-41.

27. Jensen VM, Rasmussen AW. Danish education registers. Scand J Public Health. 2011;39:91-94.

28. Bergholdt HK, Bathum L, Kvetny J, et al. Study design, participation and characteristics of the Danish General Suburban Population Study. Dan Med J. 2013;60(9):A4693.

29. Krane-Gartiser K, Breum L, Glumrr C, et al. Prevalence of the metabolic syndrome in Danish psychiatric outpatients treated with antipsychotics. Nord J Psychiatry. 2011;65(5):345-352.

30. Laursen TM, Wahlbeck K, Hallgren J, et al. Life expectancy and death by diseases of the circulatory system in patients with bipolar disorder or schizophrenia in the Nordic countries. PLoS One. 2013;8(6):e67133.

31. Nasrallah HA, Meyer JM, Goff DC, et al. Low rates of treatment for hypertension, dyslipidemia and diabetes in schizophrenia: data from the CATIE schizophrenia trial sample at baseline. Schizophr Res. 2006; 86(1-3):15-22.

32. Wysokinski A, Strzelecki D, Kloszewska I. Levels of triglycerides, cholesterol, LDL, HDL and glucose in patients with schizophrenia, unipolar depression and bipolar disorder. Diabetes Metab Syndr. 2015; 9(3):168-176.

33. De Hert M, van Winkel R, Van Eyck D, et al. Prevalence of diabetes, metabolic syndrome and metabolic abnormalities in schizophrenia over the course of the illness: a cross-sectional study. Clin Pract Epidemiol Ment Health. 2006;2:14.

34. Correll CU, Robinson DG, Schooler NR, et al. Cardiometabolic risk in patients with first-episode schizophrenia spectrum disorders: baseline results from the RAISE-ETP study. JAMA Psychiatry. 2014;71(12): 1350-1363.

35. Daumit GL, Goff DC, Meyer JM, et al. Antipsychotic effects on estimated 10-year coronary heart disease risk in the CATIE schizophrenia study. Schizophr Res. 2008;105(1-3):175-187.

36. Meyer JM, Davis VG, McEvoy JP, et al. Impact of antipsychotic treatment on nonfasting triglycerides in the CATIE schizophrenia trial phase 1. Schizophr Res. 2008;103(1-3):104-109.

37. Meyer JM, Davis VG, Goff DC, et al. Change in metabolic syndrome parameters with antipsychotic treatment in the CATIE schizophrenia trial: prospective data from phase 1. Schizophr Res. 2008;101(1-3): 273-286.
Neuropsychiatric Disease and Treatment

\section{Publish your work in this journal}

Neuropsychiatric Disease and Treatment is an international, peerreviewed journal of clinical therapeutics and pharmacology focusing on concise rapid reporting of clinical or pre-clinical studies on a range of neuropsychiatric and neurological disorders. This journal is indexed on PubMed Central, the 'PsycINFO' database and CAS,

\section{Dovepress}

and is the official journal of The International Neuropsychiatric Association (INA). The manuscript management system is completely online and includes a very quick and fair peer-review system, which is all easy to use. Visit http://www.dovepress.com/testimonials.php to read real quotes from published authors. 